\title{
Medical Care for Swimmers
}

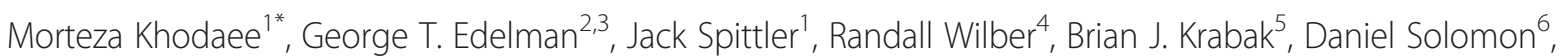 \\ Scott Riewald ${ }^{7}$, Alicia Kendig ${ }^{4}$, Laura M. Borgelt ${ }^{8}$, Mark Riederer ${ }^{9}$, Vladimir Puzovic ${ }^{10}$ and Scott Rodeo $^{11,12}$
}

\begin{abstract}
Swimming is one of the most popular sports worldwide. Competitive swimming is one of the most watched sports during the Olympic Games. Swimming has unique medical challenges as a result of a variety of environmental and chemical exposures. Musculoskeletal overuse injuries, overtraining, respiratory problems, and dermatologic conditions are among the most common problems swimmers encounter. Although not unique to swimming, overtraining is a serious condition which can have significant negative impact on swimmers' health and performance. This review article is an attempt to discuss various issues that a medical team should consider when caring for swimmers.
\end{abstract}

\section{Key Points}

- Swimming training often consists of frequent weekly practice sessions with long hours.

- Musculoskeletal overuse injuries, particularly shoulder injuries, are common among swimmers. Medical team should be aware of risk of overuse injuries, nutrition deficits, and overtraining among swimmers.

\section{Review}

\section{Introduction}

Swimming is one of the most popular sports worldwide and is the second largest sport based on the number of athletes at the Olympic Games [1]. More than 219 million people watched the 2012 Olympic Games with swimming being one of the most watched events [2]. At the Olympics, competitive swimming has pool events ranging in distance from 50 to $1500 \mathrm{~m}$ (lasting from under $20 \mathrm{~s}$ to over $15 \mathrm{~min}$ ) and official open-water swimming events that can be as long as $25 \mathrm{~km}$ (lasting more than $5 \mathrm{~h}$ ).

Despite its popularity as a sport, there is a lack of large-scale, methodologically sound, comprehensive epidemiological studies on swimming injuries and illness. Mountjoy et al. have recently published a consensus

* Correspondence: Morteza.khodaee@ucdenver.edu

${ }^{1}$ Department of Family Medicine, University of Colorado School of Medicine, Denver, CO, USA

Full list of author information is available at the end of the article statement on the definition of injury and illness in Fédération Internationale de Natation (FINA), which is the governing body for aquatic sports [1]. In this paper, we attempt to discuss medical care guideline for swimmers not only at elite level but also in a wide array of different competition and age levels [3].

While the focus of this article relates to swimmers, many principles from the guidelines (e.g., pulmonary issues and dermatoses) should be valuable for other aquatic athletes. The available scientific literature and an experienced group of experts on the topic was gathered to provide practical and sound guidelines.

\section{Physiology of Swimming}

Compared to other types of exercises, swimming is unique as it takes place in the water, which results in different gravitational and resistive forces [4]. Horizontal body position also alters the gravitational effect on circulation. Environmental factors such as water temperature have deep impacts on peripheral vascular physiology which ultimately affects the entire cardiovascular system. Respiratory physiology is also unique as breathing is restricted by stroke [4].

As in all activities, the body utilizes three main energy pathways to produce the ATP that fuels muscle contraction and swimming performance $[5,6]$. These systems are the phosphocreatine system, the anaerobic glycolytic system, and the aerobic system; details of each are provided in Table 1.

While the energy systems are associated with seemingly specific characteristics, in reality, all three systems

\section{Springer Open}


Table 1 Energy systems and their characteristics. Reproduced from Salo et al. [7] with permission

\begin{tabular}{|c|c|}
\hline & Characteristics \\
\hline \multirow[t]{3}{*}{ Anaerobic phosphocreatine } & - Fuels intense swimming lasting from 0 to $12 \mathrm{~s}$ \\
\hline & - ATP production is limited by amount of creatine-phosphate present in the muscles \\
\hline & - Generally associated with high intensity, sprint performance (e.g., 50 m) \\
\hline \multirow[t]{3}{*}{ Anaerobic glycolysis } & - Fuels high intensity swimming lasting up to $2-3$ min \\
\hline & - Generally associated sprint and middle distance swimming events (e.g., 100- and 200-m swims) \\
\hline & - An end product of anaerobic glycolysis is lactic acid \\
\hline \multirow[t]{3}{*}{ Aerobic } & - Fuels performances lasting longer than 3 min \\
\hline & $\begin{array}{l}\text { - The percentage of energy derived from fats and carbohydrates is dependent on swimming } \\
\text { intensity - the higher the intensity, the greater the reliance on glucose }\end{array}$ \\
\hline & - Generally associated with endurance activities (e.g., 400 m and longer) \\
\hline
\end{tabular}

work in concert to provide a seamless energy continuum that supports all swimming performances, with different systems contributing energy at different levels depending on the event and/or swimming intensity. Table 2 shows the relative energy contributions of each energy system for a range of maximal-effort swimming events.

It is important to note that the basic premise of training is to challenge the energy continuum so the body can adapt and enhance the way energy is produced and delivered to the muscles. As such, a majority of the training swimmers' experience is designed to develop the physiological systems that support performance. Event-specific training should be designed to achieve the following goals $[5,6]$ :

- Sprint training $(50 \mathrm{~m})$ : Enhance the capacity to produce energy through the phosphocreatine system and optimize the enzymatic processes associated with this pathway.

- Middle distance training (100-200 m events): Enhance the ability to produce energy anaerobically, which involves increasing enzymatic activity associated with anaerobic metabolism and improving the body's buffering capacity, or tolerance, for lactate.

- Distance training (400 m events and longer): Enhance lactate removal and improve the myriad cardio-respiratory functions and biochemical processes associated with delivery of oxygen to working muscle (i.e., improve $\mathrm{VO} 2 \mathrm{max}$ ).

An understanding of physiology is not only important for understanding training and competition but also relates directly to technique and how an athlete prepares for and recovers from training [7]. In a recent study, US-based coaches reported routine use of a variety of physiologic and biomechanic monitoring systems (e.g., heart monitoring, lactate monitor, 2D/3D video-based system monitor) [8]. Proper swimming mechanics will improve metabolic efficiency as propulsive forces increase and drag forces increase. Conversely, fatigue brought on by the depletion of ATP can contribute to technique breakdown and injury. Athletes must engage in a warm-up that will "prime" the cardiovascular system and prepare the body for intense training or competition. Athletes also need to warm down appropriately to remove lactate and facilitate recovery. Paradoxically, the shorter the race (and the greater the reliance on anaerobic pathways) the longer the athlete should warm down. General guidelines are to warm down for approximately $20 \mathrm{~min}$ at an intensity that gives a heart rate of about 130 beats/min [7].

\section{Nutrition}

Elite swimmers train on average $2-4 \mathrm{~h}$ per day but can often exceed 5-6 h. Due to this often variable, high level

Table 2 Relative energy system contributions to maximal performance in a range of swimming events. Reproduced from Rodrigues et al. [5] with permission

\begin{tabular}{llll}
\hline Distance $(\mathrm{m})$ & Phosphocreatine $(\%)$ & Anaerobic glycolytic (\%) & Aerobic (\%) \\
\hline 50 & $15-80$ & $2-80$ & $2-26$ \\
100 & $5-28$ & $15-65$ & $5-54$ \\
200 & $2-30$ & $25-65$ & $5-65$ \\
400 & $0-20$ & $10-55$ & $25-83$ \\
800 & $0-5$ & $25-30$ & $65-83$ \\
1500 & $0-10$ & $15-20$ & $78-90$ \\
\hline
\end{tabular}


of energy expenditure, attention to fueling and dietary intake is crucial to maximize the desired adaption from training and to enhance recovery. A periodized nutrition plan that reflects changes in training volume and intensity will support the energy and nutrient needs of the athlete. Increased attention and education is needed to ensure the swimmer achieves appropriate energy balance to prevent Relative Energy Deficiency in Sport (RED-S) which many swimmers are susceptible to, due to their high training volumes and limited recovery times [9]. Common signs and symptoms of RED-S are frequent in swimmers: increased injury risk, impaired immune system functioning, and decreased training response.

Swimmers training in the water two times per day can easily reach total calorie needs of $4000-5000 \mathrm{kcal} /$ day, despite their highly efficient stroke techniques [10]. Manipulation of dietary carbohydrate intake easily adjusts for the changes in training volume and thus energy demands, throughout the season [11]. For sprint swimmers, carbohydrate needs may only be 5-7 g of carbohydrate per $\mathrm{kg}$ of body weight, but a distance swimmer may need as high as 10-12 g of carbohydrate per $\mathrm{kg}$ body weight daily due to their heavy training loads [11, 12]. Protein needs for most swimmers are often $~ 1.4-1.8 \mathrm{~g}$ protein per kg body weight, with intakes exceeding this amount taking the place of other macronutrients (mainly carbohydrates and often essential fatty acids when caloric intake is limited). The balance of energy needs must then be met from essential fatty acid intake, preferably from plant- and fish-based sources which contain natural anti-inflammatory properties. Adequate daily consumption of nutrient dense foods (whole grains, fresh produce, and lean protein) should be encouraged for swimmers to resiliently adjust to the stress and demands of heavy training. Common micronutrient deficiencies in swimmers are low vitamin D and iron status, which can limit training quality and decrease immune system functioning $[9,13]$.

\section{Supplements}

The use of dietary supplements in the swimming world continues to grow in popularity. High training volumes, limitations of digestion time, and time constraints due to travel and fatigue from heavy training create a niche for convenience products often found in the dietary supplement form. Decreased regulation of manufacturing standards and quality assurance in dietary supplements (DSHEA Act, 1994) has increased the risk for anti-doping rule violations and health concerns as potential side effects when athletes are choosing which products to take [14]. Athletes should consult with qualified health and performance professionals before taking any sports nutrition or supplement to confirm safety and efficacy. Table 3 summarizes the three categories of available dietary supplements used in sport.

\section{Common Medical Issues Musculoskeletal}

Acute Injuries Although most musculoskeletal problems in swimming are overuse injuries due to chronic overload, there are several acute types of injury that can occur in swimmers. Most truly acute injuries occur due to contact or direct trauma and are thus uncommon in a non-contact sport such as swimming. However, this can happen in swimming due to striking the hand on the wall at the finish of a sprint. Metacarpal fractures requiring surgery have occurred in elite-level swimmers. Hand and finger contusions and fractures may also occur by striking the hand on the lane line or by striking the hand of another swimmer. Foot injuries can occur from striking the foot on the wall during a flip turn. These mechanisms of injury can also lead to lacerations.

Shoulder pain is common in swimming and is typically a chronic injury due to repetitive overuse. However, acute shoulder subluxation can occur in swimmers with underlying shoulder laxity. For example, the overhead position of the arm during hand entry in backstroke can predispose to shoulder subluxation [16, 17]. Swimmers often have some degree of underlying shoulder laxity, and this can predispose to acute subluxation. Patellar subluxation can occur in individuals with underlying generalized laxity and, although uncommon, can occur during breast stroke swimming [17]. Acute meniscus tears are uncommon in swimming, but symptoms from a degenerative meniscus tear in an older athlete may be exacerbated by breaststroke swimming due to the forceful rotatory and valgus loads on the knee [17].

Table 3 Available dietary supplements in sport. Reproduced from the Australian Institute of Sport Dietary Supplement [15] with permission

\begin{tabular}{lll}
\hline Category & Function & Examples \\
\hline Sport foods & $\begin{array}{l}\text { Convenient foods used to deliver necessary macronutrients (e.g., carbohydrates and } \\
\text { protein) before, during, and after exercise }\end{array}$ & $\begin{array}{l}\text { Protein shakes, sports drinks, gummy } \\
\text { chews, chewable tablets }\end{array}$ \\
$\begin{array}{l}\text { Medical } \\
\text { supplements }\end{array}$ & $\begin{array}{l}\text { Tablets, capsules, or liquids of essential nutrients needed to treat diagnosed conditions or } \\
\text { deficiencies affecting health and performance }\end{array}$ Iron and vitamin D supplements \\
$\begin{array}{l}\text { Performance } \\
\text { supplements }\end{array}$ & $\begin{array}{l}\text { Naturally found dietary ingredients in supplemental form taken to ergogenically aid } \\
\text { performance and recovery time }\end{array} \quad \begin{array}{l}\text { Beet juice, caffeine, beta alanine, } \\
\text { creatine, sodium bicarbonate }\end{array}$
\end{tabular}


Acute onset of back pain can occur in swimmers. The repetitive hyperextension that occurs in breaststroke and butterfly may lead to spondylolysis. Although spondylolysis is usually a chronic process, the onset of symptoms can be acute [18]. The repetitive trunk motion from flip turns may also lead to fatigue of the core stabilizing muscles, contributing to back pain [18]. Acute onset of back pain is often simply due to fatigue of the lumbar paraspinal muscles resulting from overload during swimming or dryland training. Other less common causes of acute low back pain include disc herniation and facet joint injury.

It should also be recognized that there may be an acute exacerbation of an underlying chronic condition. For example, a swimmer with shoulder tendinopathy ("swimmers shoulder") may have an acute exacerbation of shoulder pain due to a change in training volume or frequency $[16,17,19]$. A survey of injuries in a NCAA Division I collegiate swimming program reported that freshman had the highest rate of injury, supporting the relationship between a change in training and injury [20]. A careful history is critical to determine if an apparently acute presentation of pain or injury is actually an exacerbation of a pre-existing problem. Acute exacerbation of a pre-existing, chronic injury is rather common.

Swimmers often do weight lifting and other "dryland training" as part of their training program. Acute musculoskeletal injury can occur during these training activities [19]. Acute muscle strain injury can occur with forceful weightlifting or other forms of resistance exercise. Notably, a report of injuries occurring over five seasons in a
NCAA Division I collegiate swimming program found that $38 \%$ of all injuries occurred during dryland training [20]. Attention to technique and careful performance of dryland exercises is critical to prevent injury from these exercises. Relative rest of the irritated region and a focus on core strength and rehabilitation of supporting musculature is the key to treatment.

Overuse Injuries Overuse injury risk in swimmers has been reported as high as 4.0 injuries per 1000 athletic exposure (AE) [16, 19-22]. In a study of swimmers at the University of Iowa from 2002 to 2007, the shoulder and upper arm were the most commonly injured areas followed by the back and neck [20]. In the NCAA Injury Surveillance Program study for a 4-year span, the rate of overuse injuries in men was 0.66 per $1000 \mathrm{AE}$ and in women was 1.04 per $1000 \mathrm{AE}$ [22]. In a study of the 2009 FINA world championships, 171 injuries were reported (incidence of 66.0 per 1000 registered athletes) [23]. The most affected body part was the shoulder and the most common cause of injury was overuse [23].

Shoulder Shoulder pain is the most common musculoskeletal complaint in swimmers [20]. The vast majority of shoulder issues in swimmers pertain to overuse rather than from acute injuries (Fig. 1) [23, 24]. Differential diagnosis of swimmer's shoulder pain is extensive [17]. An appropriate work-up including a detailed history, and thorough physical examination of the neck, shoulder, and upper back is critical to developing and narrowing this differential. The medical practitioner must also be

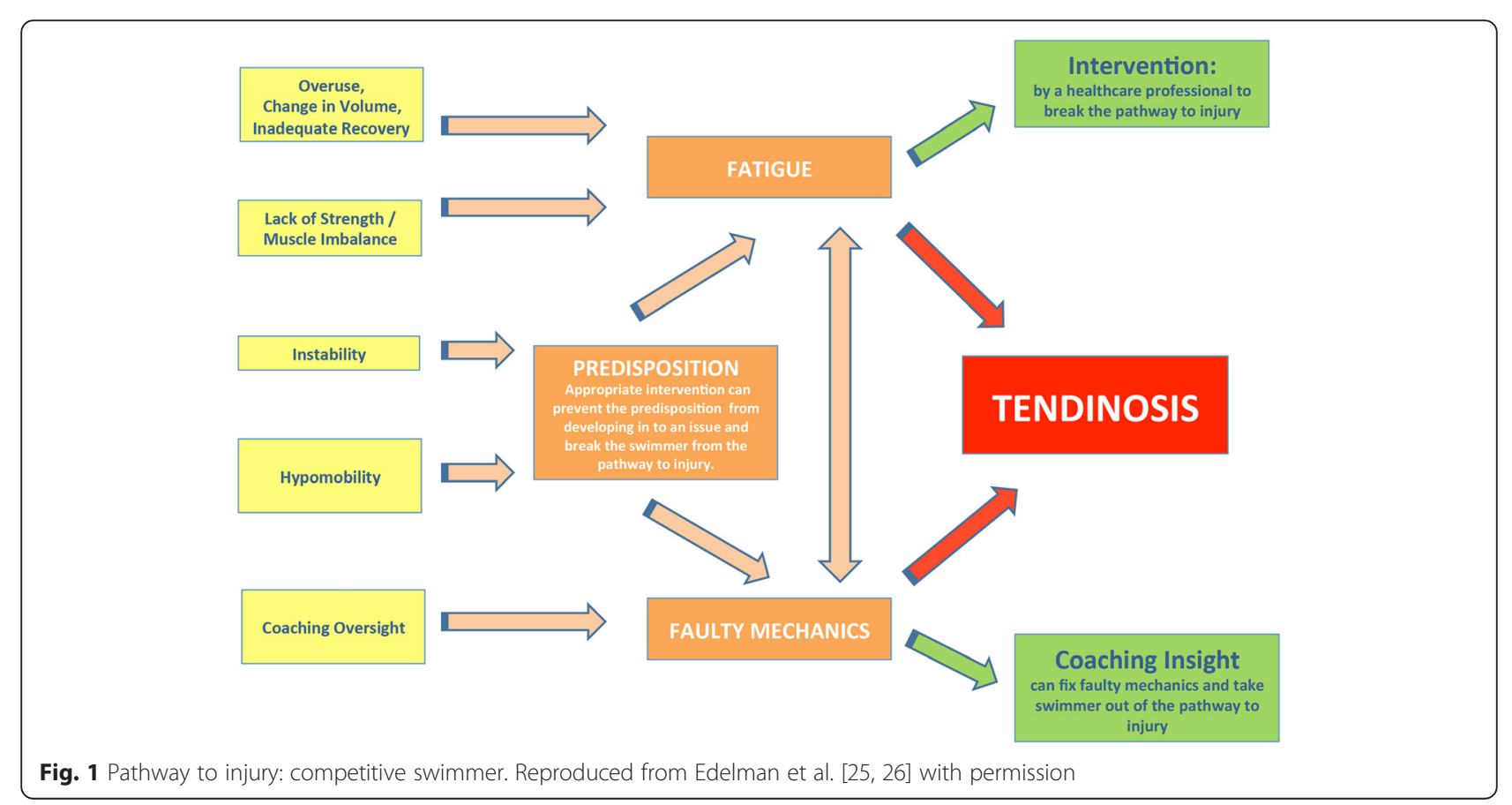


aware of physiologic stressors and biomechanics during the swim stroke similar to how we have come to understand throwing mechanics in baseball. Poor biomechanics, especially with fatigue of scapular stabilizing and rotator cuff muscles, leads to dynamic instability and impingement [19]. A multitude of issues contribute to the "swimmer's shoulder": a hypermobile glenohumeral joint combined with technique flaws or fatigue can lead to impingement of the rotator cuff [17]. Hypermobility can be multifactorial: the swimmer may have a predisposition with shoulder laxity or may have a traumatic event. Microtears or stretching of the glenohumeral ligaments exacerbate static instability. Once these athletes fatigue, their rotator cuff cannot alone stabilize the humerus and the increased translation, especially upward or superiorposterior leads to overloading the rotator cuff tendon. Abduction and rotation with humeral head translation can result in contact of the posterior supraspinatus or anterior infraspinatus against the posterior glenoid rim and labrum-a condition also described as "internal impingement." Fortunately, most of these cases can be treated with rehabilitation and a proper strengthening routine as well as improvement in potential stroke flaws [27]. A group of strength training exercises for rehabilitation of the rotator cuff, scapular stabilizers, and abdominal and low back core muscles is helpful as either preventative or rehabilitative exercises for the shoulder (Fig. 2) [19].

Hip and Groin Breaststroke, far more commonly than other competitive swimming strokes, can lead to a variety of hip and groin strains and injuries. Adductor strain, iliopsoas strains, and sports hernias pose difficult diagnostic and treatment challenges. Symptoms can be quite similar among these entities. Given the repetitive nature of swimming, these can also be notoriously problematic over an extended time [28]. Stretching and

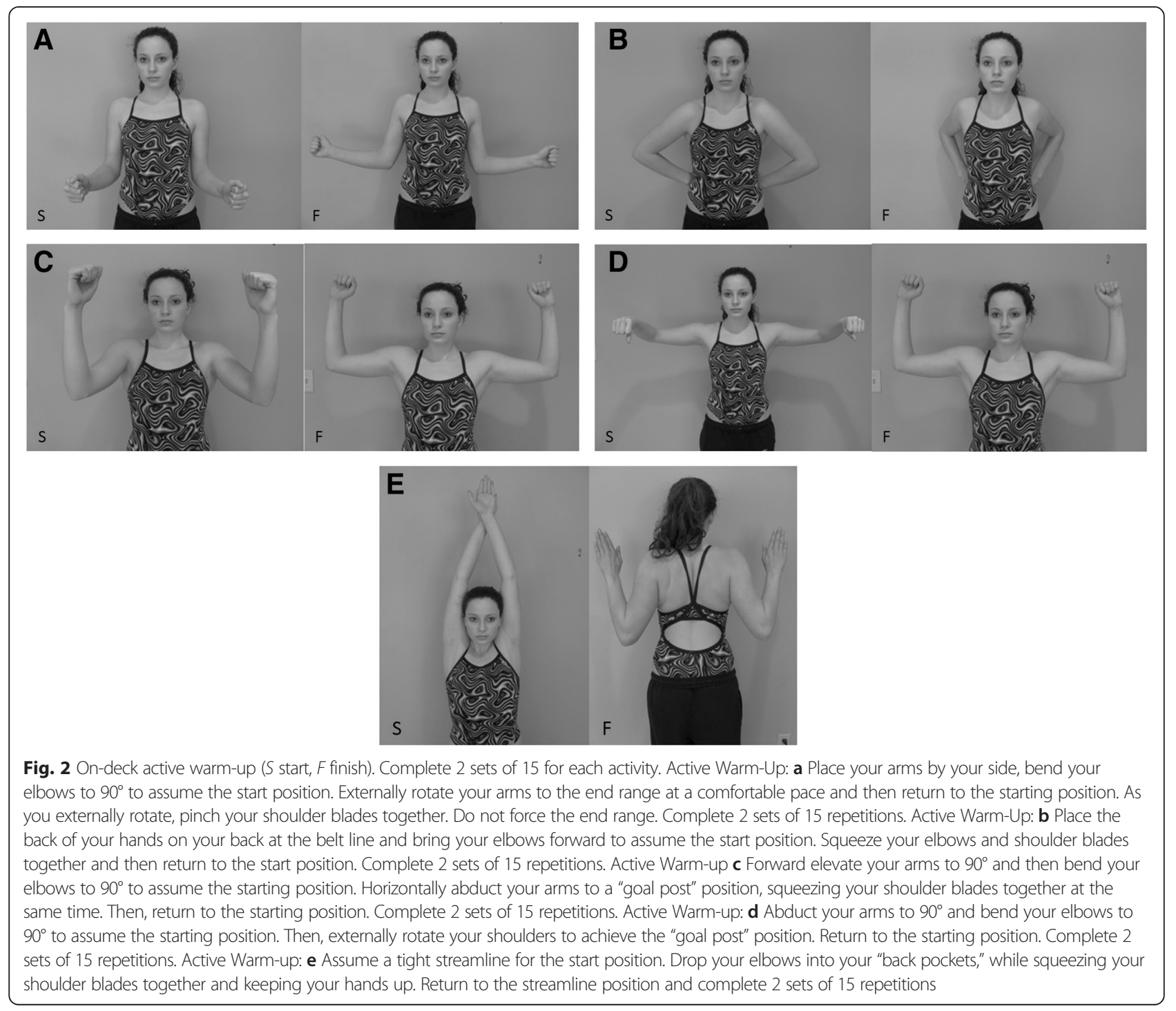


supportive core strengthening will aid in recovery. A narrower breaststroke kick will decrease strain on the hip adductor muscles [29]. This can be facilitated using a number of technique drills in the pool. Prophylactic stretching and strengthening is always better than treating an issue.

Knee Up to $75 \%$ of breaststrokers report medial knee pain [30]. Medial knee pain can occur from strain on the medial collateral ligament, irritation of a medial plica, or, in unusual cases, medial meniscus tears. Patellar instability is another less common differential diagnosis to consider. Examination of the knee should be focused on evaluation of knee stability. Knee injuries from crosstraining such as weight-lifting, plyometrics, or running can be exacerbated by swimming. Improving hip flexibility and avoidance of an overly wide breaststroke kick will help decrease strain on these areas of the knee.

Lumbar Spine Dolphin kicking plays an important role in modern swimming technique. With an increased emphasis on this facet of swimming comes risk of low back injury, as hyperextension with dolphin kicking can lead to pars interarticularis pathologies (e.g., spondylolysis). The L5-S1 disc is another common area of irritation with overuse. Similar to other areas of overuse in swimmers, dryland training, especially weightlifting, can exacerbate or cause back injuries [31,32]. Also, similar to other areas of overuse, a prevention program with emphasis on core abdominal and low back strengthening can help prevent chronic low back complaints.

Shoulder Rehabilitation Changes in training practices and improved research allow healthcare providers to manage shoulder pain in competitive swimmers better than ever before. In the past, the healthcare providers generally attributed shoulder pain to excessive training or too many repetitive overhead strokes leading to laxity and resultant impingement of the rotator cuff [33-37]. Recently, a new treatment paradigm reveals no single cause for shoulder pain in swimmers but rather a cluster of contributing factors that can match the clinical presentation to the treatment [27]. Edelman et al. offers a subclassification system for shoulder pain identifying a cluster of etiological factors: (1) predisposition, (2) fatigue, (3) injury-related (faulty) mechanics, and (4) tendinopathy [27]. This model can guide the selection of homogenous subgroups for more effective treatment strategies as noted in Fig. 1. Identifying individual causes in the setting of this paradigm should allow targeted and more effective treatment.

Shoulder Stretching and Dynamic Warm-Up The shoulder is the most frequently stretched joint among swimmers. To date, swimmers have adopted stretches that target the static stabilizers of the GHJ. In the past, static stretches and pre-race rituals (i.e., ballistic windmill motion) were utilized in hopes of preventing injury [38]. Recent research on swimmer's flexibility suggests there is no indication that extraordinary shoulder joint motion or flexibility is necessary to achieve a fast, efficient stroke [39, 40]. In addition, there is no evidence that static stretching immediately before activity will reduce muscle injury rates [41, 42]. Many swimmers are generally flexible and possess loose connective tissue (general joint laxity) [43]. Because of their inherent laxity, swimmers should emphasize preserving the overall stability of the shoulder and less time on general static stretches [26]. Instead, a dynamic warm-up (Fig. 2) has been found to produce short-term and long-term performance enhancements in power, agility, strength, muscle endurance, and anaerobic capacity [26, 38, 44, 45]. A dynamic warm-up tends to include some form of dynamic stretching, agility, and plyometric activities and specific motor pattern movements [46]. Figure 2 demonstrates dynamic warm-up which is specifically designed for the swimming population. Swimmers should employ a steady pace with each activity and avoid ballistic type motions.

Focused Strengthening Exercises Dryland training has been an important part of strengthening programs among swimmers at different age and skill levels. The main focus of these training programs seems to be the spine and core strengthening [47]. Strength deficits can play an important role in fatigue development. Madsen et al. found that the majority of swimmers demonstrated signs of scapular dyskinesis in the course of a 100-min swimming session [48]. Through EMG analysis of the painful shoulder, Scovazzo et al. discovered muscle activity of the serratus anterior is significantly depressed through the important pull-through phase in swimmers with shoulder pain [49]. Batahla revealed in the course of a swim season the internal rotators of competitive swimmers become proportionally stronger when compared to their antagonists, increasing muscle imbalance, and the risk of an injury process $[50,51]$. Fatigue may lead to a short-term decrease in acromiohumeral distance [52]. As a result, a dryland program focusing on the shoulder external rotators and the scapular stabilizers would be of benefit and should be recommended as routine prophylactic measures [53]. Strengthening the internal rotators should be de-emphasized.

Return to Swimming after Injury If the treatment program results in removing the swimmer from the water, then a careful reintegration back to training is essential $[54,55]$. During the rehabilitation process, when the 
swimmer is able to reach above shoulder height without pain and demonstrate resisted motions from $0^{\circ}$ to $90^{\circ}$ without pain, then the swimmer is encouraged to return to the pool and swim 1000-2000 m slowly and comfortably while avoiding antagonizing strokes and sprint sets. When the swimmer is without pain during resisted motions in all planes, and during most activities of daily living and swimming $2000 \mathrm{~m}$, then add $500 \mathrm{~m}$ every three workouts. During this step, it is indicated to avoid double workouts and sprint sets. When swimming 4000-5000 m without pain, then integrate all four competitive strokes and add short sprint sets.

\section{Pulmonary}

To ensure the health of swimmers, chlorine-based disinfectants are used to effectively reduce the risk of bacterial and viral infection in swimming pool facilities. However, when chlorine reacts with organic compounds in the pool water (e.g., sweat, urine, soap residues, cosmetics, suntan oil, dirt, and other solid waste material), several volatile chemical compounds are produced in the form of trihalomethanes, chloramines, and haloacetic acids [56]. In turn, exposure to these chemical compounds can occur in swimmers via three direct avenues: (a) ingestion of pool water, (b) inhalation of airborne chlorine and chlorine analogs in the air space located immediately above the pool surface, and (c) direct skin contact with the pool water [57]. Exposure to trihalomethanes, chloramines, and haloacetic acids can have a negative impact on general health and athletic performance. Specifically, there is strong evidence suggesting that acute and/or chronic exposure to these chlorine-based chemical compounds can manifest as clinical symptoms of upper respiratory dysfunction (chronic rhinitis, sneezing, irritated nasal sinuses, runny nose, nasal obstruction, and sinusitis) [58, 59] and lower respiratory dysfunction (breathing difficulty, wheezing, cough, chest tightness, and abnormal spirometry) $[58,60,61]$, as well as eye irritation and headache [62]. The negative effects of exposure to chlorine-based chemical compounds on pulmonary function appear to be due to pathophysiological mechanisms related to lung epithelial tissue perturbation [63-65] and airway remodeling [66, 67]. Thus, swimmers face a tough balancing act between the positive effects of a contaminant-free pool and the negative aspects of over-exposure to chlorine and chlorine analogs. Table 4 summarizes the recommendations for potential strategies to control the negative effects of swimming pool chlorine on general health and performance.

One study reported that about $20 \%$ of elite swimmers (FINA world championships and Olympic Games) had asthma/airway hyperresponsiveness [68]. In this study, swimmers in comparison to other aquatic athletes had higher prevalence of asthma. This seems to be more
Table 4 Recommendations to athletes, coaches, and medical staff as potential strategies for controlling the negative effects of swimming pool chlorine on general health and performance

Schedule training sessions in outdoor pools as much as possible where natural ventilation helps to reduce surface chlorine levels. If forced to use an indoor pool, avoid older pools that may have low ceilings and poor ventilation systems. In addition, deck-level industrial fans can be effective in enhancing the clearance of surface chlorine in older, poorly ventilated pools.

Undergo evaluation of pulmonary function by a certified medical professional for the purpose of determining asthmatic response and/or susceptibility to airway hyper-reactivity in a chlorinated environment $[57,67]$.

Consider prophylactic use of antioxidant supplementation (beta-carotene, vitamin $C$, vitamin E) to reduce the negative effects of chlorine-induced oxidative stress on pulmonary function [69].

Train in a pool where the professional maintenance staff is conscientious and precise in their regulation of optimal chlorine levels, as well as water temperature and ventilation of surface chlorine.

Train in a pool where the professional staff ensures that proper swimming pool behavior, etiquette, and equipment are in place to help reduce the level of chlorine exposure. Posted requirements should be in place regarding pre-entry showers, bathroom breaks, suntan lotion, swim caps, goggles, etc.

Encourage swimming pool maintenance staff to stay current on the latest information regarding the efficacy of potential substitute disinfectant methods such as electro-physical systems (electrolytic copper and electrolytic silver), ozone disinfection, and ultraviolet disinfection [56].

related to the endurance nature of swimming and not necessarily due to chlorines [68].

Exercise-induced bronchospasm (EIB) is more common among swimmers in comparison to general population $[68,69]$. This may be partially due to more participation as a result of a belief that breathing the warm and humidified air benefits swimmers with asthma and EIB [17]. However, exposure to aerosol chemicals may trigger these conditions [17]. Management of swimmers with asthma and EIB is similar to other athletes [17, 70]. Finally, along with EIB, assessment of exercise-induced laryngeal obstruction (EILO) should also be included in the medical workup of swimmers who present with chronic pulmonary issues [71].

\section{Ear, Nose, and Throat}

Allergic and non-allergic rhinosinusitis is common among swimmers [72]. Due to easy spread and possible other factors (e.g., suppressed immune system), viral upper respiratory infection (URI) is more common among swimmers than other athletes $[17,70]$. Swimmers with symptoms and signs of more serious infections (e.g., pneumonia, fevers, and hypoxia) should not be allowed to practice.

Prolonged exposure to water and frequent attempt to clean the ear canal predispose swimmers to develop acute otitis externa (swimmer's ear). Gram-negative bacteria, most commonly pseudomonas, are the major pathogens. Treatment with otic anesthetic/anti-inflammatory/ antibiotic/acidifier agents is usually adequate [73]. In rare 
cases with systemic signs (e.g., fever), oral antibiotics may be necessary [73]. Other less common ear problems in swimmers include otomycosis, exostoses ("surfer's ear"), traumatic tympanic membrane perforation, otitis media, and barotraumas of the inner ear.

\section{Dermatologic}

Swimmers are susceptible to different dermatologic conditions given their substantial amount of time spent in the water and in moist environments [74]. Certain dermatoses are infection or organism-related. Swimming pool granulomas (atypical Mycobacterium infection) may occur overlying bony prominences and are often found in the upper extremities, especially the fingers. Nodules or plaques arise about 6 weeks after exposure [75]. The affected area should soak in warm, clean water for 5-10 min, three to four times per day. Antibiotics (clarithromycin, minocycline) may also be used [76]. "Hot tub" (pseudomonas aeruginosa) folliculitis usually appears within 8-48 h of exposure to contaminated water. Pale green fluorescence under Wood's lamp can aid in diagnosis [77]. Most eruptions self-resolve within 2 weeks, but acetic acid $5 \%$ compresses may provide symptomatic relief [78]. Deep bacterial folliculitis ("bikini bottom") may arise in swimmers who wear wet, tight-fitting swimsuits for long periods of time. Maceration of the skin allows for infection with Streptococcus or Staphylococcus aureus. This can be usually treated with a course of cephalexin or appropriate MRSA coverage, if suspected [79]. Swimmers are also particularly vulnerable to other common skin infections such as molluscum contagiosum ("water warts"), tinea pedis ("athlete's foot"), and plantar warts [74].

Other swimming-related dermatoses may be caused by irritants or allergies. Goggles are often an offending agent, caused by reaction to the foam, rubber, or plastic lining [80]. A short course of medium-potency topical steroid or an oral steroid burst for swimmers with severe symptoms may be used [74]. Chlorinated or brominated pool water may cause an allergic or irritant contact dermatitis. This can be treated by attempting to avoid the chemical irritant or by typical contact dermatitis care (i.e., moisturizers, topical corticosteroids).

Frictional dermatitis may occur from rubbing the chin on the shoulder when turning the head to breathe or with recurrent contact on rough pool surfaces with hands/feet ("pool palms") [81, 82]. Lesions generally selfresolve, but petroleum jelly may help alleviate symptoms. Finally, it is important to note that swimmer's may be at an increased risk for skin cancers, such as melanoma. This is due to sun exposure with the effects possibly potentiated by chlorine [83]. Therefore, it is important to counsel outdoor swimmers on adequate use of water-resistant or water-proof sunscreen.

\section{Ophthalmologic}

The most common ophthalmologic issue encountered by swimmers is eye irritation and redness related to chemicals contained in swimming pools. This is more commonly experienced in pools containing chlorine or bromine compared to those using ozone, UV, and salt electrolysis treatments [84]. Wearing swim goggles significantly decreases the risk of developing eye irritation [85]. In addition to peri-orbital skin irritation, some studies have shown a small but significant transient increase in intraocular pressure (IOP) in individuals wearing certain types of swimming goggles. Goggles with smaller surface areas lead to larger IOP measurements [86]. Despite some speculation that repetitive goggle use over time could consequently lead to development of glaucoma, one recent study challenges this notion [87]. Another ophthalmologic issue in swimmers is ocular infection. Swimmers wearing soft contact lenses are at risk of developing pseudomonas infection and acanthamoeba keratitis [88, 89]. Acanthamoeba infection is rare but serious. Symptoms may include eye pain/redness, blurred vision, light sensitivity, foreign body sensation, and excessive tearing. Suspected patients should be referred to an ophthalmologist immediately for evaluation, as early detection is essential [88]. Treatment usually consists of topical agents; however, sometimes oral itraconazole therapy and/or surgery may be required in advanced cases [88]. Prevention consists of contact lens removal during swimming or thorough disinfection of lenses following swimming.

\section{Neurologic}

The main concerning neurologic condition for swimmers is epilepsy. Having a seizure in the water could result in serious immersion-related injury and ultimately drowning. Therefore, it is widely accepted that swimmers with epilepsy should always be supervised while swimming [90]. This is especially important in those athletes with poorly controlled seizure disorders. If an athlete does have a seizure in the water, it is important to extricate them to land as quickly as possible to minimize immersion injury and practice standard seizure care such as body injury prevention and airway management. Even after apparent full recovery, near drowning victims are at risk of major delayed complications, such as secondary drowning [91]. Therefore, all athletes who experience a seizure in the water should be evaluated and monitored at a medical facility.

Often swimmers (more common among synchronized swimmers) will train by holding their breath for extended periods of time in effort to increase respiratory capacity. This may be dangerous as it can result in loss of consciousness and potentially anoxic brain injury [92]. Swimmers should be counseled that these "blackouts" 
can be dangerous and possibly result in permanent damage.

\section{Concussion}

Though uncommon, the recognition and appropriate treatment of the concussed athlete is essential in preventing long-term sequelae. The incidence of concussions vary for high school $($ men $=0.1$ per $10,000 \mathrm{AE} /$ women 0.2 per $10,000 \mathrm{AE}$ ) [93], collegiate ( $\mathrm{men}=0.6 \mathrm{per}$ $10,000 \mathrm{AE} /$ women 0.1 per 10,000 AE) [22, 94], and international levels (0.04 per 10,000 athletes). Concussion may occur from a variety of reasons (e.g., when a backstroke swimmer strikes the wall, runs into another swimmer while entering in the water or collision with the ground) [93]. Symptoms are similar to other sports (i.e., headache, nausea, vomiting, and dizziness), and any athlete suspected of a concussion should be removed from practice/competition [95]. Successful management of the concussed swimmer requires coordination of services by a sports medicine provider and team experienced in concussion care. Athletes should initiate a return to school program when appropriate and be symptom free prior to the initiation of a return to swimming/dryland training [95]. All athletes should follow a gradual return to play program that incorporates progression of swimming activity while monitoring symptoms [95]. Any athlete experiencing prolonged symptoms, specific deficits, or multiple concussions may require further cognitive testing prior to returning to swimming.

\section{Endocrine and Metabolic}

Menstrual Cycle and Contraception The prevalence of menstrual disorders in sports like swimming ranges from 16 to $82 \%$ [96-98]. Several etiologic factors may contribute to menstrual disorders including abnormal levels of hormones, luteinizing hormone ( $\mathrm{LH})$ pulsatility, inadequate body fat stores, low-energy availability (EA), and exercise stress [9]. Function hypothalamic amenorrhea occurs through reductions in EA which may disrupt LH pulsatility by impacting the hypothalamic hormone gonadotropin-releasing hormone output and alter the menstrual cycle. During extensive training, rapid or significant fat mass reduction may adversely affect menstrual function. Low EA alters levels of metabolic hormones and substrates including insulin, cortisol, growth hormone, insulin-like growth factor-I (IGF-I), 3,3,5-triiodothyronine, grehlin, leptin, peptide tyrosinetyrosine, glucose, fatty acids, and ketones.

In the past studies, female competitive swimmers not only appeared vulnerable to delayed puberty and menstrual irregularities but the associated hormonal profile was also very different from the hypothalamic amenorrhea described in dancers and runners. Specifically, dehydroepiandrostenedione sulfate and androstenedione, but not testosterone, were higher than average in swimmers compared with controls [96]. Mild hyperandrogenism, rather than hypoestrogenism, was a suggested mechanism for reproductive dysfunction in swimmers. Furthermore, the prevalence of amenorrhea in runners is $24-26 \%$ compared with swimmers at $12 \%$ [99]. This may be related to the emphasis of leanness in running compared with swimming.

Sports performance during various phases of the menstrual cycle has been researched for many years. Evidence-based conclusions have been extremely difficult to reach due to methodological issues (e.g., inappropriate verification of menstrual cycle phase, timing of hormone samples), inter- and intraindividual variability in hormone concentrations, pulsatile secretion of hormones, and small numbers of subjects. Research has not consistently demonstrated significant differences in aerobic capacity, anaerobic capacity, aerobic endurance, or muscle strength in any specific menstrual cycle phase [100, 101]. However, very active or highly competitive swimmers are at risk of developing the RED-S (formerly known as female athlete triad) which is a syndrome resulting from relative energy deficiency that affects many aspects of physiological function including metabolic rate, menstrual function, bone health, immunity, protein synthesis, cardiovascular, and psychological health [9]. In athletes with amenorrhea for over 6 months, bone mineral density (BMD) should be measured with dual X-ray absorptiometry (DXA). Weight gain, with adequate protein and carbohydrate intake, has been the strongest predictor for return of normal menstrual function in college athletes [102].

The use of contraceptives may be advantageous for swimmers who are negatively affected by their menstrual cycle, as they can provide a stable and controllable hormonal environment for training and competition. Furthermore, swimmers may desire minimal or no bleeding/spotting which can be offered with several different forms of contraception. Examples of long-acting reversible contraceptives with high (>99\%) efficacy include intrauterine devices (IUDs) and the implant [103]. Progestin-only IUDs offer the advantage of minimal to no menstrual bleeding. Injectable depot medroxyprogesterone may cause amenorrhea and adversely affect BMD if used long term ( $>2$ years) [104]. Continuous or extended use of combined (containing estrogen and progestin) hormonal contraceptives can be used for the pill, patch, or ring to avoid menstrual bleeding. Instructions for this include continuous use of a monophasic (same amount of estrogen and progestin) contraceptive by using only active pill, vaginal ring, or patch and discarding inactive pills or skipping the ring-free or patch-free week. Some combined hormonal contraceptive pills are packaged to allow for a menstrual cycle every 3 months with 84 active pills and 7 inactive pills. Although an oral 
contraceptive may be a less desirable form of contraception due to lower efficacy (91\%) and masking low EA and menstrual dysfunction, the use of oral contraceptives has shown no effects on swimming or endurance performance. Therefore, combined contraceptives should be recommended only when there is a medical indication or other more effective contraceptives (e.g., IUD, implant) are contraindicated, not tolerated, or unacceptable to the swimmer.

Diabetes Mellitus Participating in regular physical activity among patients with type 1 and type 2 diabetes mellitus improves blood glucose control, lipid profile, blood pressure, and fitness $[105,106]$. Swimmers with diabetes should be able to compete in endurance events granted that they have no complications of their diabetes and are in good glycemic control [105, 107, 108]. When planning medical coverage, it is crucial to be aware of swimmers with diabetes in advance. Medical teams should be prepared to manage unusual but serious circumstances such as hypoglycemia [107, 108]. Close glycemic and dietary monitoring before and during long practice sessions and races is the key to avoid complications [109]. As insulin is on the prohibited WADA list, a therapeutic use exemption is required.

\section{Cold- and Heat-Related IIIness}

Cold- and heat-related illness is greatly impacted by a variety of factors that can affect the swimming athlete. Both occur when there is a thermoregulatory mismatch between heat production from exercise and heat loss. Body heat loss in the swimmer primarily occurs through convection from the interface of the skin and water that is proportional to speed (heat transfer coefficient) and the temperature difference between the skin and water [110]. Other factors impacting heat loss include the design and thermal properties of garments, the environment (air temperature, humidity), athlete illness, and medications [111, 112].

Pool and open-water venues offer unique environmental challenges for the swimmer. Pool venue environments are often well controlled when in a closed setting but can be impacted by weather (temperature, wind, and humidity) when in an open setting. Open-water swimming venues have greater environmental variability (air and water temperature, humidity, and sun exposure) that can fluctuate during the course of a race leading to hypothermia or hyperthermia. FINA guidelines suggest open-water swimmers should only compete when the water temperature is above $16{ }^{\circ} \mathrm{C}$ or below $31{ }^{\circ} \mathrm{C}$ to minimize the risk of severe hypothermia or hyperthermia, respectively [110]. Additionally, the impact of cold water immersion and voluntary apnea could result in parasympathetic and sympathetic activity resulting in cardiac arrhythmias, pulmonary edema, and potential death.

The evaluation, treatment, and prevention of environmental-related illnesses require a coordinated effort between the athlete, sports medicine providers, and venue managers. Symptoms will vary for hyperthermia (fatigue, fever, chills, elevated temperature, thirst, confusion, and tachycardia) and hypothermia (chills, fatigue, confusion, and bradycardia). All athletes should undergo removal of wet or damp clothing and have a rectal temperature measurement to obtain an accurate core temperature [111]. Athletes with a temperature $>40{ }^{\circ} \mathrm{C}$ should undergo cold water immersion as soon as possible to normalize core temperature. Athletes with hypothermia should be warmed with heat blankets/air, as appropriate. Any athletes with cardiovascular compromise will require transportation to a local hospital. Preventive strategies include acclimatization, familiarity with the race venue, adequate warm-up time, and proper hydration [111].

\section{Overtraining}

Overtraining (OT) is a condition experienced by many swimmers, especially those competing at the Olympic level [113]. OT is characterized by several physiological, biological, and psychological symptoms with the most obvious ones being (a) a consistent decrement in performance, (b) an inability to train and recover effectively, and (c) a loss of determination and mental focus [114]. OT can be more accurately portrayed as the end-point on a continuum [114], as shown in Fig. 3. Moving from left to right, the first three phases on the OT continuum are reflective of "positive" training and good performance, analogous to green on a traffic light ("proceed immediately"). Next on the OT continuum, separated by a thin line is a phase that typically includes both "positive" and "negative" training/performance, due primarily to a requisite increase in training load for the purpose of advancing the athlete's fitness level and competitive performance. This block is analogous to yellow/amber on a traffic light ("proceed with caution"). Finally, on the far right of the OT continuum is OT, which is characterized by "negative" training/performance, analogous to red on a traffic light ("stop"). There are several models that have been proposed to explain the underlying biological, physiological, and/or psychological mechanisms of OT. Among the more credible is the "elevated pro-inflammatory cytokine" hypothesis [115-117]. This model proposes that excessive musculoskeletal stress (two or three training sessions per day for several weeks) in combination with insufficient recovery (sleep, nutrition, psychological down time) leads to chronic musculoskeletal inflammation and the release of the following pro-inflammatory cytokines: interleukin-6 (IL-6), interleukin-1-beta (IL-1 $\beta$ ), and tumor necrosis 


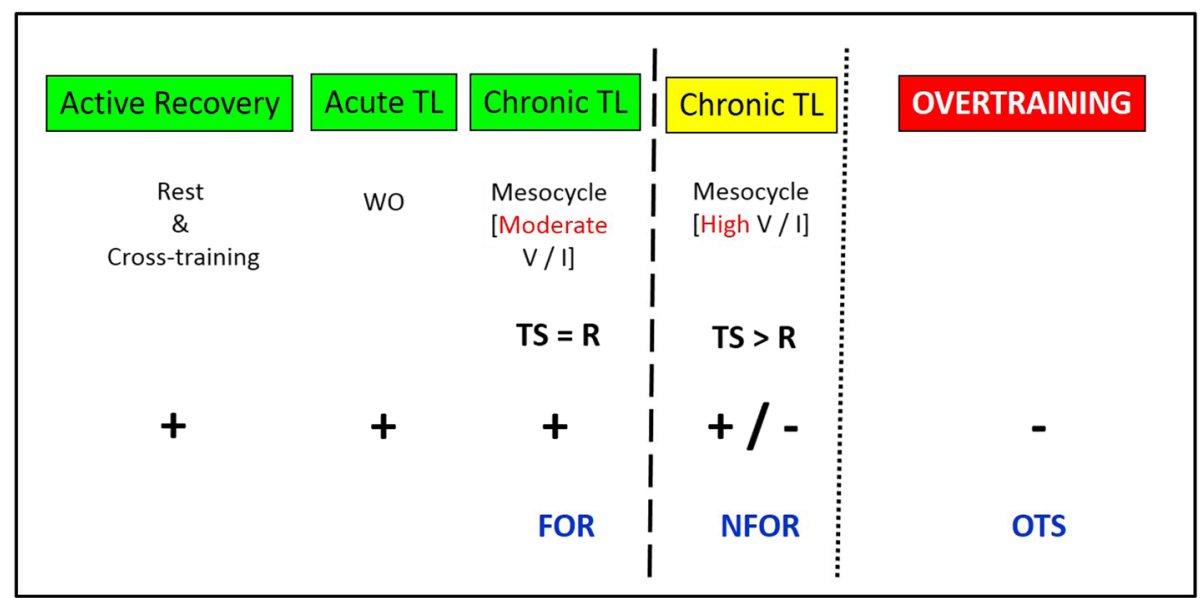

TL, Training Load; WO, Workout; V, Volume; I, Intensity; TS, Training Stimulus; R, Recovery; FOR, Functional Overreaching; NFOR, Non-Functional Overreaching; OTS, Overtraining Syndrome; +, Positive Training; -, Negative Training

Fig. 3 Overtraining continuum. Reproduced from Wilber et al. [114] with permission

factor-alpha (TNF- $\alpha)$. These pro-inflammatory cytokines act on the central nervous system (CNS), hypothalamicpituitary-adrenal (HPA) axis, and hypothalamic-pituitarygonadal (HPG) axis, which manifests in several of the clinical symptoms seen in overtrained athletes (e.g., sleep disturbances, elevated stress hormones, perturbed reproductive function) [115-117]. In terms of the prevention of OT, we offer a medically based and practical treatment algorithm, as shown in Fig. 4 [114].

\section{Child, Adolescent, and Masters Swimmers}

The young and Masters athlete represent two special populations of swimmers that present unique conditions in their medical care. Swimming is an excellent activity for the young athlete that not only promotes physical activity but also helps build psychosocial and academic skills. For the Masters athlete, swimming improves physical performance without impact on the weight bearing joints that may contribute to degenerative joint disease.

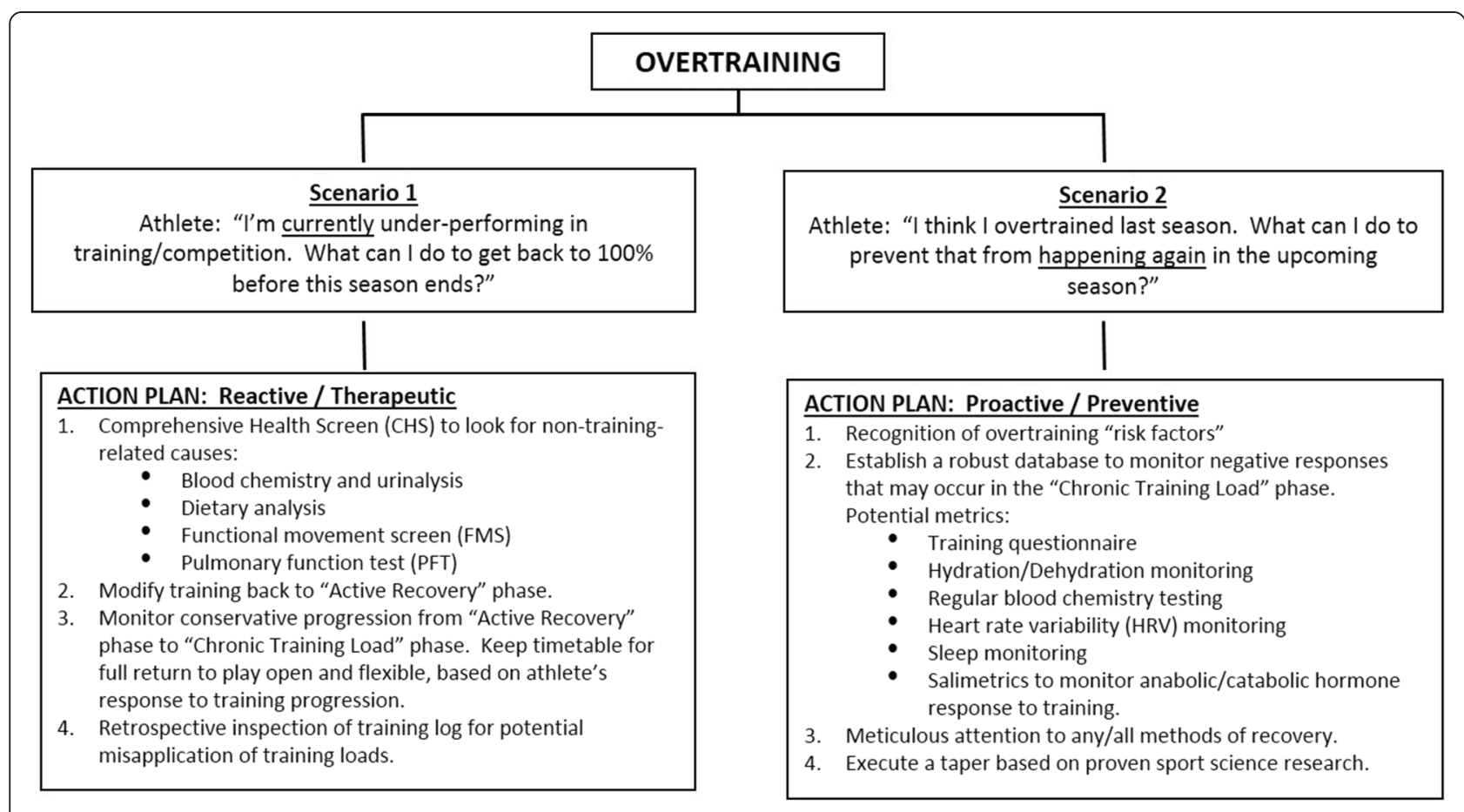

Fig. 4 Overtraining treatment algorithm. Reproduced from Wilber et al. [114] with permission 
In addition, regular physical activity and training regimens often delay and blunt the aging-related declines in aerobic and anaerobic fitness. However, swimming can have a negative impact on the health and safety of both groups.

Early sports specialization, OT, and burnout are various conditions that commonly affect the young swimming athlete. Increasing desires by parents, guardians, coaches, and young athletes often drive more intensive and earlier training schedules. Athletes as young as 11 years are swimming $>25 \mathrm{~h}$ per week in the pool. Training schedules often include swimming several hours in the morning, going to school, and then swimming several hours after school. Some young athletes are swimming 20-30 km per week, which has an aerobic equivalent to running $100 \mathrm{~km}$. Many young athletes swim all year round, with only 1 day off of swimming per week. This intensive training schedule, combined with early sports specialization, can lead to a significant risk for overuse injuries as well as mental and physical burnout. Female and male athletes are at risk for the RED-S if they are not consuming enough calories from both daily and exercise activities. Young athletes that exhibit decreasing performance emotional or behavior changes, or have prolonged recovery from common overuse injuries may be experiencing OT or burnout. Sports medicine physicians are encouraged to counsel their young athletes to take at least 1-2 days off from sports per week, not to specialize in one sport until late adolescence, and to spend 2-3 calendar months participating in another sport [118-121]. Additionally, young athletes should not spend more hours training than their chronological age per week [121]. The IOC recently published recommendations on youth athlete development [122].

Participation in swimming by the Masters athlete has become an increasingly popular sport, with the United States Masters Swimming (USMS) as the governing body [123]. Swimming offers the Masters athlete the opportunity to improve their physical conditioning and delay the most common chronic diseases of the aging population which include arthritis, hypertension, and heart disease. The physiology of aging puts the Masters athlete at a unique disadvantage in comparison to the younger athlete $[121,124]$. Most importantly are the changes in the cardiovascular (decreased maximal heart rate, decreased cardiac output), pulmonary (decreased total lung capacity, decreased maximal oxygen uptake), and musculoskeletal (decreased strength and bulk, decreased flexibility) system. Sex-related performance differences are less significant among female elite swimmers with advanced age in comparison to counterpart marathon runners [125]. Medications that interfere with blood pressure and heart rate may also influence performance and safety for the Masters athlete. Masters athletes are at risk for the same overuse injuries seen in the young athlete; however, the recovery and rehabilitation from these injuries may be prolonged. Thus, it is important to recognize these injuries early to prevent further progression. Rehabilitation from injuries is even more critical for the Masters athlete to prevent more rapid loss of flexibility, strength, and endurance than seen in younger athletes [121].

\section{Near-Drowning and Drowning}

Drowning is the major cause of death worldwide (449,000 in 2000) and the second leading cause of unintentional death in children and adolescents in the USA [126, 127]. Children should be taught to swim. Children younger than 5 years of age should be supervised all the time, as instruction in younger children may lead to a false sense of security [127]. Additional counseling techniques include never swimming alone, swimming with adult supervision, the use of an approved personal floatation device, and the risks of the consumption of alcohol and other drugs [127]. A lifeguard or someone familiar with cardiopulmonary resuscitation (CPR) should be present during each practice and competition [127].

\section{Open-Water Swimming}

The unique environmental conditions of open-water swimming inherently belie the potential injuries. In addition, marathon swimming, with some competitions greater than $25 \mathrm{~km}$, adds interesting physiologic conditions that can affect competitors [11]. With training, most open-water swimmers do longer-distance workouts, also increasing potential for overuse injuries.

As with pool swimming, the most likely cause of injury is overuse of the shoulder in training. The highest incompetition injury risk of any aquatic discipline at the FINA World Championship was reported to be openwater swimming [23]. The risk of an in-competition injury was 57.7/1000 starts of female athletes with most of those being contact injuries with another athlete resulting in contusion.

Environmental conditions such as water/air temperature, water quality, and aquatic fauna and flora create the most unique aspect of open-water swimming [125]. Poor water quality can result in gastrointestinal illness. This can cause dehydration especially given the inability of athletes to frequently hydrate during races. Animal exposure (e.g., jellyfish, rays, fish, sharks, dolphin, seals, snakes) can all be problematic [128]. Because swimmers will be in the water for such long periods, prevention of chaffing and rubbing of the skin is important [128]. Exhaustion and fatigue can possibly exacerbate pre-existing medical conditions. This can be notable in both recreational as well as elite swimmers. 
Lastly, the team and swimmer are reliant on training and race support. On most open-water courses, the swimmer is some distance from coaches and land-based medical personnel, relying on lifeguards and other, usually boat-based, observers. However, boats, including those of support crew and media covering events can unintentionally injure swimmers if in proximity. Communication between the athlete, coach, and support crew is usually minimal.

Keys to providing optimal medical care at open-water training and competitions include planning for the temperature, current, and other water conditions as well as endemic threats [128]. This can include providing hydration on course such as via boat supports. Preparing, briefing, and executing a medical response and evacuation plan are paramount.

\section{Conclusions}

Swimming continues to draw athletes of all ages and competition levels. Traditionally, long hours and frequent practice sessions are common training programs among young and elite swimmers. This places swimmers at high risk for developing overuse injuries, nutrition deficits, and OT. Medical, coaching, and administrative staff, as well as athletes and parents, should be familiar with symptoms and signs of these conditions. More robust and methodologically sound studies are needed to help create comprehensive and evidence-based guidelines for taking care of swimmers.

\section{Acknowledgements}

No financial support was received for the conduct of this study or preparation of this manuscript.

\section{Authors' Contributions}

MK carried out the concept/design, literature review, manuscript preparation, critical revision of the manuscript, and approval of the article. SRo, JS, and BK contributed to the literature review, manuscript preparation, critical revision of the manuscript, and approval of the article. GE, RW, DS, SRi, AK, LB, MR, and VP contributed to the literature review, manuscript preparation, critical revision of some parts of the manuscript, approval of the article.

\section{Competing Interests}

Scott Rodeo owns a stock in Cayenne Medical and Rotation Medical, Inc. The authors declare that they have no competing interests.

\section{Consent for Publication}

Written, informed consent for the publication of the images in Fig. 2 was obtained from the person depicted.

\section{Author details}

'Department of Family Medicine, University of Colorado School of Medicine, Denver, CO, USA. ${ }^{2}$ Edelman Spine \& Orthopaedic Physical Therapy, Dover, DE, USA. ${ }^{3}$ Department of Physical Therapy, University of Delaware, Newark, DE, USA. ${ }^{4}$ United State Olympic Committee, Colorado Springs, CO, USA. ${ }^{5}$ Rehabilitation, Orthopedics and Sports Medicine, University of Washington and Seattle Children's Sports Medicine, Seattle, WA, USA. ${ }^{6}$ Marin Orthopedics and Sports Medicine, Novto, CA, USA. 'Winter Sports, United States Olympic Committee, Colorado Springs, CO, USA. ${ }^{8}$ Department of Clinical Pharmacy and Family Medicine, University of Colorado Skaggs School of Pharmacy and School of Medicine, Aurora, CO, USA. ${ }^{9}$ Department of Pediatrics and
}

Orthopaedic Surgery, University of Michigan, Ann Arbor, MI, USA. ${ }^{10}$ Faculty of Medical Sciences, University of Kragujevac, Kragujevac, Serbia. ${ }^{11}$ Sports Medicine and Shoulder Service, Orthopaedic Surgery, The Hospital for Special Surgery, Weill Medical College of Cornell University, New York, NY, USA.

${ }^{12}$ Tissue Engineering, Regeneration, and Repair Program, The Hospital for Special Surgery, Weill Medical College of Cornell University, New York, NY, USA.

Received: 12 May 2016 Accepted: 7 July 2016

Published online: 25 July 2016

\section{References}

1. Mountjoy M, Junge A, Alonso JM, Clarsen B, Pluim BM, Shrier I, et al. Consensus statement on the methodology of injury and illness surveillance in FINA (aquatic sports). Br J Sports Med. 2016;50(10):590-6.

2. Gustafson M. NBC record ratings prove swimming's viability. 2012.

3. Dijkstra HP, Geertsema L, Benzarti N, van Dorssen EA, van den Hoogenband CR, Mountjoy M. Review of the Local Organizing Committee (LOC) medical services during the 12th FINA World Swimming Championships $(25 \mathrm{~m})$ in Doha, Qatar. Br J Sports Med. 2016;50(10):613-8.

4. Holmer I. Swimming physiology. Ann Physiol Anthropol. 1992;1 (3):269-76.

5. Rodrigues F, Mader A. Energy Systems in Swimming. In: Seifert L, Chollet D, Mujika I, editors. World Book of Swimming: From Science to Performance. New York: Nova Science Publishers Inc.; 2011. p. 224-54.

6. Stager JM, Stickford J, Grand K. Energy Systems and Physiology. In: Riewald S, Rodeo S, editors. The Science of Swimming Faster. Champaign: Human Kinetics Publishers; 2015. p. 147-72.

7. Salo D, Riewald S. Complete Conditioning for Swimming. Champaign: Human Kinetics Publishers; 2008.

8. Mooney R, Corley G, Godfrey A, Osborough C, Newell J, Quinlan LR, et al. Analysis of swimming performance: perceptions and practices of US-based swimming coaches. J Sports Sci. 2016;34(11):997-1005.

9. Mountjoy M, Sundgot-Borgen J, Burke L, Carter S, Constantini N, Lebrun C, et al. The IOC consensus statement: beyond the Female Athlete Triad-Relative Energy Deficiency in Sport (RED-S). Br J Sports Med. 2014;48(7):491-7.

10. Costill DL, Kovaleski J, Porter D, Kirwan J, Fielding R, King D. Energy expenditure during front crawl swimming: predicting success in middle-distance events. Int J Sports Med. 1985;6(5):266-70.

11. Shaw G, Koivisto A, Gerrard D, Burke LM. Nutrition considerations for open-water swimming. Int J Sport Nutr Exerc Metab. 2014;24(4):373-81

12. American Dietetic A, Dietitians of C, American College of Sports M, Rodriguez NR, Di Marco NM, Langley S. American College of Sports Medicine position stand. Nutrition and athletic performance. Med Sci Sports Exerc. 2009:41(3):709-31.

13. Panel FNE, Fina. FINA-Yakult consensus statement on nutrition for the aquatic sports. Int I Sport Nutr Exerc Metab. 2014;24(4):349-50.

14. Dickinson A. History and overview of DSHEA. Fitoterapia. 2011;82(1):5-10.

15. Australian Sports Commission. Australian Institute of Sport (AIS) dietary supplement protocol. Available at: http://www.ausport.gov.au/ais/nutrition/ supplements/classification. Accessed July 2016.

16. Hill L, Collins M, Posthumus M. Risk factors for shoulder pain and injury in swimmers: A critical systematic review. Phys Sportsmed. 2015;43(4):412-20.

17. Nichols AW. Medical Care of the Aquatics Athlete. Curr Sports Med Rep. 2015;14(5):389-96.

18. Nyska M, Constantini N, Cale-Benzoor M, Back Z, Kahn G, Mann G. Spondylolysis as a cause of low back pain in swimmers. Int J Sports Med. 2000;21(5):375-9.

19. Wanivenhaus F, Fox AJ, Chaudhury S, Rodeo SA. Epidemiology of injuries and prevention strategies in competitive swimmers. Sports Health. 2012;4(3):246-51.

20. Wolf $B R$, Ebinger $A E$, Lawler MP, Britton CL. Injury patterns in Division I collegiate swimming. Am J Sports Med. 2009;37(10):2037-42.

21. Jones JH. Swimming overuse injuries. Phys Med Rehabil Clin N Am. 1999;10(1):77-94. vi.

22. Kerr ZY, Baugh CM, Hibberd EE, Snook EM, Hayden R, Dompier TP. Epidemiology of National Collegiate Athletic Association men's and women's swimming and diving injuries from 2009/2010 to 2013/2014. Br J Sports Med. 2015;49(7):465-71.

23. Mountjoy M, Junge A, Alonso JM, Engebretsen L, Dragan I, Gerrard D, et al. Sports injuries and illnesses in the 2009 FINA World Championships (Aquatics). Br J Sports Med. 2010;44(7):522-7. 
24. Engebretsen $L$, Soligard $T$, Steffen $K$, Alonso JM, Aubry M, Budgett R, et al. Sports injuries and illnesses during the London Summer Olympic Games 2012. Br J Sports Med. 2013;47(7):407-14.

25. Edelman G. Stability is the key: warm-ups and stretches for the competitive swimmers. Swimmer. 2010 (January-February):22-7. Available at: http://www. usmsswimmer.com/201001/swimmer_stretching.pdf. Accessed July 2016.

26. Edelman G, Pink M, Gemmell B. The Mechanics of Swimming: Treating Swimmers with Painful Shoulders. EDUCATA (online course); 2015. Available at: https://www.educata.com/courseprofile.aspx?g=57. Accessed July 2016.

27. Richardson AB, Jobe FW, Collins HR. The shoulder in competitive swimming Am J Sports Med. 1980;8(3):159-63.

28. Grote K, Lincoln TL, Gamble JG. Hip adductor injury in competitive swimmers. Am J Sports Med. 2004;32(1):104-8.

29. Holmich P. Long-standing groin pain in sportspeople falls into three primary patterns, a "clinical entity" approach: a prospective study of 207 patients. Br J Sports Med. 2007;41(4):247-52. discussion 52.

30. Kenal KA, Knapp LD. Rehabilitation of injuries in competitive swimmers. Sports Med. 1996;22(5):337-47.

31. De Luigi AJ. Low back pain in the adolescent athlete. Phys Med Rehabil Clin N Am. 2014;25(4):763-88.

32. Micheli $L J$, Wood R. Back pain in young athletes. Significant differences from adults in causes and patterns. Arch Pediatr Adolesc Med. 1995;149(1):15-8.

33. Bak K. Nontraumatic glenohumeral instability and coracoacromial impingement in swimmers. Scand J Med Sci Sports. 1996;6(3):132-44.

34. Bak K. The practical management of swimmer's painful shoulder: etiology, diagnosis, and treatment. Clin J Sport Med. 2010;20(5):386-90.

35. Ciullo JV. Swimmer's shoulder. Clin Sports Med. 1986;5(1):115-37.

36. Rupp S, Berninger $K$, Hopf T. Shoulder problems in high level swimmers-impingement, anterior instability, muscular imbalance? Int J Sports Med. 1995;16(8):557-62.

37. Zemek MJ, Magee DJ. Comparison of glenohumeral joint laxity in elite and recreational swimmers. Clin J Sport Med. 1996;6(1):40-7.

38. McMillian DJ, Moore JH, Hatler BS, Taylor DC. Dynamic vs. static-stretching warm up: the effect on power and agility performance. J Strength Cond Res. 2006;20(3):492-9.

39. Borsa PA, Scibek JS, Jacobson JA, Meister K. Sonographic stress measurement of glenohumeral joint laxity in collegiate swimmers and age-matched controls. Am J Sports Med. 2005;33(7):1077-84.

40. Sein ML, Walton J, Linklater J, Appleyard R, Kirkbride B, Kuah D, et al. Shoulder pain in elite swimmers: primarily due to swim-volume-induced supraspinatus tendinopathy. Br J Sports Med. 2010;44(2):105-13.

41. Pope RP, Herbert RD, Kirwan JD, Graham BJ. A randomized trial of preexercise stretching for prevention of lower-limb injury. Med Sci Sports Exerc. 2000;32(2):271-7.

42. Thacker SB, Gilchrist J, Stroup DF, Kimsey Jr CD. The impact of stretching on sports injury risk: a systematic review of the literature. Med Sci Sports Exerc. 2004;36(3):371-8.

43. Jansson A. The Impact of age and gender with respect to general joint laxity, shoulder joint laxity and rotation - A study of 9, 12 and 15 year old students. Stockholm: Department of Surgical Sciences, Section of Sports Medicine; 2005

44. Bishop D. Warm up II: performance changes following active warm up and how to structure the warm up. Sports Med. 2003;33(7):483-98.

45. Herman SL, Smith DT. Four-week dynamic stretching warm-up intervention elicits longer-term performance benefits. J Strength Cond Res. 2008;22(4):1286-97.

46. Aguilar AJ, DiStefano LJ, Brown CN, Herman DC, Guskiewicz KM, Padua DA A dynamic warm-up model increases quadriceps strength and hamstring flexibility. J Strength Cond Res. 2012;26(4):1130-41.

47. Krabak BJ, Hancock KJ, Drake S. Comparison of dry-land training programs between age groups of swimmers. PM R. 2013;5(4):303-9.

48. Madsen PH, Bak K, Jensen S, Welter U. Training induces scapular dyskinesis in pain-free competitive swimmers: a reliability and observational study. Clin J Sport Med. 2011;21(2):109-13.

49. Scovazzo ML, Browne A, Pink M, Jobe FW, Kerrigan J. The painful shoulder during freestyle swimming. An electromyographic cinematographic analysis of twelve muscles. Am J Sports Med. 1991;19(6):577-82.

50. Batalha N, Marmeleira J, Garrido N, Silva AJ. Does a water-training macrocycle really create imbalances in swimmers' shoulder rotator muscles? Eur J Sport Sci. 2015;15(2):167-72
51. Batalha NM, Raimundo AM, Tomas-Carus P, Barbosa TM, Silva AJ. Shoulder rotator cuff balance, strength, and endurance in young swimmers during a competitive season. J Strength Cond Res. 2013;27(9):2562-8.

52. Chopp JN, O'Neill JM, Hurley K, Dickerson CR. Superior humeral head migration occurs after a protocol designed to fatigue the rotator cuff: a radiographic analysis. J Shoulder Elbow Surg. 2010;19(8):1137-44.

53. Batalha N, Raimundo A, Tomas-Carus P, Paulo J, Simao R, Silva AJ. Does a land-based compensatory strength-training programme influences the rotator cuff balance of young competitive swimmers? Eur J Sport Sci. 2015:15(8):764-72.

54. Hamman S. Considerations and return to swim protocol for the pediatric swimmer after non-operative injury. Int J Sports Phys Ther. 2014;9(3):388-95.

55. Spigelman T, Sciascia A, Uhl T. Return to swimming protocol for competitive swimmers: a post-operative case study and fundamentals. Int J Sports Phys Ther. 2014;9(5):712-25.

56. Zarzoso M, Llana S, Perez-Soriano P. Potential negative effects of chlorinated swimming pool attendance on health of swimmers and associated staff. Biol Sport. 2010;27(4):233-40.

57. Wilber RL. Unhealthy air and water environments: effects on endurance training and competition. In: Mujika I, editor. Endurance Training: Science and Practice. Vitoria-Gasteiz: Teamwork Media Espana; 2012. p. 280-91.

58. Bougault V, Boulet LP. Airway dysfunction in swimmers. Br J Sports Med. 2012;46(6):402-6.

59. Deitmer T, Scheffler R. Nasal physiology in swimmers and swimmers' sinusitis. Acta Otolaryngol. 1990;110(3-4):286-91.

60. Martin N, Lindley MR, Hargadon B, Monteiro WR, Pavord ID. Airway dysfunction and inflammation in pool- and non-pool-based elite athletes. Med Sci Sports Exerc. 2012;44(8):1433-9.

61. Turcotte H, Langdeau JB, Thibault G, Boulet LP. Prevalence of respiratory symptoms in an athlete population. Respir Med. 2003;97(8):955-63.

62. Bougault $V$, Turmel J, Levesque B, Boulet LP. The respiratory health of swimmers. Sports Med. 2009:39(4):295-312.

63. Helenius IJ, Rytila P, Metso T, Haahtela T, Venge P, Tikkanen HO. Respiratory symptoms, bronchial responsiveness, and cellular characteristics of induced sputum in elite swimmers. Allergy. 1998;53(4):346-52.

64. Kippelen $\mathrm{P}$, Anderson SD. Airway injury during high-level exercise. $\mathrm{Br} \mathrm{J}$ Sports Med. 2012;46(6):385-90.

65. Levesque B, Duchesne JF, Gingras S, Lavoie R, Prud'Homme D, Bernard E, et al. The determinants of prevalence of health complaints among young competitive swimmers. Int Arch Occup Environ Health. 2006;80(1):32-9.

66. Martin JG, Campbell HR, lijima H, Gautrin D, Malo JL, Eidelman DH, et al. Chlorine-induced injury to the airways in mice. Am J Respir Crit Care Med. 2003;168(5):568-74.

67. Rundell KW, Anderson SD, Sue-Chu M, Bougault V, Boulet LP. Air quality and temperature effects on exercise-induced bronchoconstriction. Compr Physiol. 2015;5(2):579-610.

68. Mountjoy M, Fitch K, Boulet LP, Bougault V, van Mechelen W, Verhagen E. Prevalence and characteristics of asthma in the aquatic disciplines. J Allergy Clin Immunol. 2015:136(3):588-94.

69. Kippelen P, Fitch KD, Anderson SD, Bougault V, Boulet LP, Rundell KW, et al. Respiratory health of elite athletes - preventing airway injury: a critical review. Br J Sports Med. 2012;46(7):471-6.

70. Boulet LP, O'Byrne PM. Asthma and exercise-induced bronchoconstriction in athletes. N Engl J Med. 2015;372(7):641-8.

71. Hull JH, Scadding G, Dickinson J, Greenwell J. Medical Care of AQUATIC Athlete-Do Not Overlook the Upper Airway. Curr Sports Med Rep. 2016;15(1):46.

72. Gelardi M, Ventura MT, Fiorella R, Fiorella ML, Russo C, Candreva T, et al. Allergic and non-allergic rhinitis in swimmers: clinical and cytological aspects. Br J Sports Med. 2012;46(1):54-8.

73. Rosenfeld RM, Schwartz SR, Cannon CR, Roland PS, Simon GR, Kumar KA, et al. Clinical practice guideline: acute otitis externa. Otolaryngol Head Neck Surg. 2014;150(1 Suppl):S1-S24.

74. Tlougan BE, Podjasek JO, Adams BB. Aquatic sports dermatoses: part 1. In the water: freshwater dermatoses. Int J Dermatol. 2010:49(8):874-85.

75. Ang P, Rattana-Apiromyakij N, Goh CL. Retrospective study of Mycobacterium marinum skin infections. Int J Dermatol. 2000;39(5):343-7.

76. Adams BB. Skin infections in athletes. Dermatol Nurs. 2008;20(1):39-44.

77. Amichai B, Finkelstein E, Halevy S. Early detection of Pseudomonas infection using a Wood's lamp. Clin Exp Dermatol. 1994;19(5):449. 
78. Green JJ. Localized whirlpool folliculitis in a football player. Cutis. 2000;65(6):359-62.

79. Basler RS, Basler DL, Basler GC, Garcia MA. Cutaneous injuries in women athletes. Dermatol Nurs. 1998;10(1):9-18. quiz 9-20.

80. Romaguera C, Grimalt F, Vilaplana J. Contact dermatitis from swimming goggles. Contact Dermatitis. 1988;18(3):178-9.

81. Koehn GG. Skin injuries in sports medicine. J Am Acad Dermatol. 1991;24(1):152.

82. Wong LC, Rogers M. Pool palms. Pediatr Dermatol. 2007;24(1):95.

83. Nelemans PJ, Rampen FH, Groenendal H, Kiemeney LA, Ruiter DJ, Verbeek AL. Swimming and the risk of cutaneous melanoma. Melanoma Res. 1994;4(5):281-6.

84. Fernandez-Luna A, Burillo P, Felipe JL, Del Corral J, Garcia-Unanue J, Gallardo L. Perceived health problems in swimmers according to the chemical treatment of water in swimming pools. Eur J Sport Sci. 2015;21:1-10.

85. Kelsall HL, Sim MR. Skin irritation in users of brominated pools. Int J Environ Health Res. 2001;11(1):29-40.

86. Morgan WH, Cunneen TS, Balaratnasingam C, Yu DY. Wearing swimming goggles can elevate intraocular pressure. $\mathrm{Br} J$ Ophthalmol. 2008;92(9):1218-21.

87. Franchina M, Yazar S, Booth L, Wan SL, Cox K, Kang MH, et al. Swimming goggle wear is not associated with an increased prevalence of glaucoma. $\mathrm{Br}$ J Ophthalmol. 2015;99(2):255-7.

88. Jiang C, Sun $X$, Wang Z, Zhang Y. Acanthamoeba keratitis: clinical characteristics and management. Ocul Surf. 2015;13(2):164-8.

89. Bremond-Gignac D, Chiambaretta F, Milazzo S. A European perspective on topical ophthalmic antibiotics: current and evolving options. Ophthalmol Eye Dis. 2011;3:29-43.

90. Diekema DS, Quan L, Holt VL. Epilepsy as a risk factor for submersion injury in children. Pediatrics. 1993:91(3):612-6.

91. Milne S, Cohen A. Secondary drowning in a patient with epilepsy. BMJ. 2006:332(7544):775-6.

92. Lindholm P, Lundgren CE. The physiology and pathophysiology of human breath-hold diving. J Appl Physiol (1985). 2009;106(1):284-92.

93. Marar M, Mcllvain NM, Fields SK, Comstock RD. Epidemiology of concussions among United States high school athletes in 20 sports. Am J Sports Med. 2012;40(4):747-55

94. Zuckerman SL, Kerr ZY, Yengo-Kahn A, Wasserman E, Covassin T, Solomon GS. Epidemiology of Sports-Related Concussion in NCAA Athletes From 2009-2010 to 2013-2014: Incidence, Recurrence, and Mechanisms. Am J Sports Med. 2015;43(11):2654-62.

95. McCrory P, Meeuwisse W, Aubry M, Cantu B, Dvorak J, Echemendia RJ, et al. Consensus statement on concussion in sport-the 4th International Conference on Concussion in Sport held in Zurich, November 2012. Clin J Sport Med. 2013;23(2):89-117

96. Constantini NW, Warren MP. Menstrual dysfunction in swimmers: a distinct entity. J Clin Endocrinol Metab. 1995;80(9):2740-4.

97. Faunoo P, Kalund S, Kanstrup IL. Menstrual patterns in Danish elite swimmers. Eur J Appl Physiol Occup Physiol. 1991;62(1):36-9.

98. Schtscherbyna A, Soares EA, de Oliveira FP, Ribeiro BG. Female athlete triad in elite swimmers of the city of Rio de Janeiro, Brazil. Nutrition. 2009;25(6):634-9.

99. Lebrun CM. Menstrual cycle dysfunction. official statements by the American College of Sports Medicine concerning topics of interest to the public at large: ACSM. Available at: https://www.acsm.org/docs/ currentcomments/menstrualcycledysfunction.pdf. Accessed July 2016.

100. Lebrun CM, Rumball JS. Relationship between athletic performance and menstrual cycle. Curr Womens Health Rep. 2001;1(3):232-40.

101. Smekal G, von Duvillard SP, Frigo P, Tegelhofer T, Pokan R, Hofmann P, et al. Menstrual cycle: no effect on exercise cardiorespiratory variables or blood lactate concentration. Med Sci Sports Exerc. 2007;39(7):1098-106.

102. Arends JC, Cheung MY, Barrack MT, Nattiv A. Restoration of menses with nonpharmacologic therapy in college athletes with menstrual disturbances: a 5-year retrospective study. Int J Sport Nutr Exerc Metab. 2012;22(2):98-108.

103. Guttmacher Institute. Contraceptive use in the United States. 2015. Available at: https://www.guttmacher.org/fact-sheet/contraceptive-use-united-states. Accessed July 2016.

104. Committee Opinion No. 602. Depot medroxyprogesterone acetate and bone effects. Obstet Gynecol. 2014;123(6):1398-402.

105. American Diabetes A. Physical activity/exercise and diabetes. Diabetes Care. 2004;27 Suppl 1:S58-62.
106. Chansky ME, Corbett JG, Cohen E. Hyperglycemic emergencies in athletes. Clin Sports Med. 2009;28(3):469-78.

107. Devadoss M, Kennedy L, Herbold N. Endurance athletes and type 1 diabetes. Diabetes Educ. 2011:37(2):193-207.

108. Robertson K, Riddell MC, Guinhouya BC, Adolfsson P, Hanas R, International Society for P, et al. ISPAD Clinical Practice Consensus Guidelines 2014. Exercise in children and adolescents with diabetes. Pediatr Diabetes. 2014;15 Suppl 20:203-23.

109. Marcason W. Is there a recommended target range for blood glucose for the type 1 diabetic endurance athlete? J Acad Nutr Diet. 2012;112(12):2092.

110. Bergeron MF, Bahr R, Bartsch P, Bourdon L, Calbet JA, Carlsen KH, et al. International Olympic Committee consensus statement on thermoregulatory and altitude challenges for high-level athletes. $\mathrm{Br} J$ Sports Med. 2012;46(11):770-9.

111. Asplund CA, O'Connor FG, Noakes TD. Exercise-associated collapse: an evidence-based review and primer for clinicians. Br J Sports Med. 2011; 45(14):1157-62.

112. Pryor RR, Bennett BL, O'Connor FG, Young JM, Asplund CA. Medical Evaluation for Exposure Extremes: Heat. Clin J Sport Med. 2015;25(5):437-42.

113. Meeusen R, Duclos M, Foster C, Fry A, Gleeson M, Nieman D, et al. Prevention, diagnosis, and treatment of the overtraining syndrome: joint consensus statement of the European College of Sport Science and the American College of Sports Medicine. Med Sci Sports Exerc. 2013;45(1):186-205.

114. Wilber RL. Overtraining and recovery. In: Riewald S, Rodeo S, editors. Science of Swimming Faster. Champaign: Human Kinetics; 2015. p. 261-81.

115. Lakier SL. Overtraining, excessive exercise, and altered immunity: is this a T helper-1 versus T helper-2 lymphocyte response? Sports Med. 2003;33(5):347-64.

116. Smith LL. Cytokine hypothesis of overtraining: a physiological adaptation to excessive stress? Med Sci Sports Exerc. 2000;32(2):317-31.

117. Smith LL. Tissue trauma: the underlying cause of overtraining syndrome? J Strength Cond Res. 2004;18(1):185-93.

118. Brenner JS, American Academy of Pediatrics Council on Sports M, Fitness. Overuse injuries, overtraining, and burnout in child and adolescent athletes. Pediatrics. 2007;119(6):1242-5.

119. DiFiori JP, Benjamin HJ, Brenner J, Gregory A, Jayanthi N, Landry GL, et al. Overuse injuries and burnout in youth sports: a position statement from the American Medical Society for Sports Medicine. Clin J Sport Med. 2014;24(1):3-20.

120. Jayanthi NA, LaBella CR, Fischer D, Pasulka J, Dugas LR. Sports-specialized intensive training and the risk of injury in young athletes: a clinical case-control study. Am J Sports Med. 2015;43(4):794-801.

121. Myer GD, Jayanthi N, Difiori JP, Faigenbaum AD, Kiefer AW, Logerstedt D, et al. Sport Specialization, Part I: Does Early Sports Specialization Increase Negative Outcomes and Reduce the Opportunity for Success in Young Athletes? Sports Health. 2015;7(5):437-42.

122. Bergeron MF, Mountjoy M, Armstrong N, Chia M, Cote J, Emery CA, et al. International Olympic Committee consensus statement on youth athletic development. Br J Sports Med. 2015:49(13):843-51.

123. Miller JW. Injuries and considerations in masters aquatics sports. Clin Sports Med. 1999;18(2):413-26. viii-ix.

124. Akkari A, Machin D, Tanaka H. Greater progression of athletic performance in older Masters athletes. Age Ageing. 2015;44(4):683-6.

125. Senefeld J, Joyner MJ, Stevens A, Hunter SK. Sex differences in elite swimming with advanced age are less than marathon running. Scand J Med Sci Sports. 2015.

126. Peden MM, McGee K. The epidemiology of drowning worldwide. Inj Control Saf Promot. 2003;10(4):195-9.

127. Weiss J, American Academy of Pediatrics Committee on Injury V, Poison P. Prevention of drowning. Pediatrics. 2010;126(1):e253-62.

128. Gerrard DF. Open water swimming. Particular medical problems. Clin Sports Med. 1999:18(2):337-47. vii. 